\title{
A invasão da União na competência dos Estados e do Distrito Federal na contribuição de intervenção no domínio econômico incidente sobre a importação e a comercialização de petróleo e seus derivados, gás natural e seus derivados, e álcool combustível
}

\author{
Norberto Leonelli Neto ${ }^{1}$ \\ Bruno Vagaes ${ }^{2}$
}

\begin{abstract}
Resumo
Pretende este estudo demonstrar a inconstitucionalidade da Emenda à Constituição n.. 33/01, responsável por introduzir no Texto Magno o $§ 4$ o do Art. 177, o qual traz os critérios materiais da hipótese de incidência da Contribuição de Intervenção no Domínio Econômico sobre a Importação e a Comercialização de Petróleo e seus Derivados, Gás Natural e seus Derivados e Álcool Combustível. Busca-se comprovar o problema ocorrente no critério material comercializar, em razão do qual a União, competente para instituição da referida Contribuição, estaria invadindo a competência dos Estados e do Distrito Federal, conforme o disposto no Art. 155, II, da Carta Maior. Para tanto, esta Contribuição, comprovada sua natureza tributária, recebe na análise o tratamento de imposto revestido pelo nome de Contribuição, dada sua hipótese de incidência, bem como a base de cálculo, características que revelam a referida natureza e que são próprias dos impostos. Aplicável a esta Contribuição o regime jurídico dos impostos, infere-se que a União não pode tributar por via desta hipótese de incidência, na ocorrência do critério material comercializar, pois reservado constitucionalmente aos Estados e ao Distrito Federal por ocasião da cobrança do Imposto sobre Circulação de Mercadorias. Sendo a Emenda à Constituição n.o33/01 manifestação do Poder Constituinte Derivado Reformador, veículo introdutor de normas apto a ser objeto de controle de constitucionalidade, chega-se à conclusão de que a mesma é inconstitucional.
\end{abstract}

Palavras-Chave: Contribuição; Competência; Natureza jurídica; Comercializar; Inconstitucionalidade.

\section{Introdução}

- A Contribuição de Intervenção no Domínio Econômico sobre a Importação e a Comercialização de Petróleo e seus Derivados, Gás Natural e seus Derivados, e Álcool Combustível, foi introduzida no Ordenamento Jurídico brasileiro pela Emenda Constitucional 33 de

\footnotetext{
Estudante de Direito da UEL.
}

2 Estudante de Direito da UEL. 
11 de Dezembro de 2.001, que acrescentou o § 4ㅇa art 177 da Constituição Federal, dispondo:

$\S 4$ 으 A lei que instituir contribuição de intervenção no domínio econômico relativa às atividades de importação ou comercialização de petróleo e seus derivados, gás natural e seus derivados e álcool combustível deverá atender aos seguintes requisitos:

I - a alíquota da contribuição poderá ser

a) diferenciada por produto ou uso;

b)reduzida e restabelecida por ato do Poder Executivo, não se the aplicando o disposto no art. 150,III, b;

II - os recursos arrecadados serão destinados:

a) ao pagamento de subsídios a preços ou transporte de álcool combustível, gás natural e seus derivados e derivados de petróleo;

b) ao financiamento de projetos ambientais relacionados com a indústria do petróleo e do gás;

c) ao financiamento de programas de infra-estrutura de transportes.

O presente estudo será direcionado a apontar a inconstitucionalidade caracterizada pelo critério material da hipótese de incidência: Comercializar, pelo qual a União, está invadindo a competência reservada aos Estados e do Distrito Federal, conforme disposição do Art 155, II da Constituição Federal.

Para chegar-se a essa conclusão, é necessário realizar um estudo traçando a Competência Tributaria das Pessoas Políticas atribuídas pela Constituição Federal, afirmando a característica da Privatividade das Competências.

Ademais, é preciso definir se a CIDE dos combustíveis, como também é chamada, reveste-se de natureza jurídica de tributo, sendo verdadeira contribuição ou um imposto revestido pelo nome de contribuição e qual o regime jurídico a ela aplicável.

Será analisado o critério material da hipótese de incidência. Apesar de sua bivalência, para o presente estudo, apenas interessará o critério material definido pelo verbo comercializar, uma vez que é idêntico ao critério matéria do ICMS, previsto no Art 155 , da CF, como imposto de competência dos Estados e do Distrito Federal. 
A invasão da União na competência dos Estados e do Distrito Federal na contribuição de intervenção do domínio econômico incidente sobre a importação e a comercialização de petróleo e seus derivados, gás natural e seus derivados, e álcool combustível

Por fim, será apontada se realmente há inconstitucionalidade da CIDE dos combustíveis em relação ao critério material comercializar, pela invasão União na competência dos Estados e do Distrito Federal.

\section{Da competência tributária}

No Brasil, decorrente da afirmação do Princípio Federativo e do Principio da Autonomia Municipal e Distrital, a Constituição Federal distribuiu entre as pessoas políticas, competência a cada uma das pessoas políticas, para legislar, de forma a inovar o ordenamento jurídico nacional, respeitando os Princípios e Normas Constitucionais.

Estas competências estão delineadas por todo o corpo da Lei das Leis brasileira, ficando cada ente federativo com uma parcela.

Dentre estas competências está a competência tributária, onde a Constituição Federal determina qual pessoa política tem o direito de produzir quais normas jurídicas de direito tributário.

Assim, cada pessoa política tem uma parcela da competência tributaria, não podendo invadir a competência reservada a outra.

Lembre-se que a Constituição ao afirmar que uma pessoa política possui determinada competência tributaria, implica em negar a mesma competência para as demais. Por exemplo, ao afirmar que compete a União instituir impostos sobre a importação de produtos estrangeira, limita-a a esta pessoa política, implicando em uma negação quanto às demais.

Roque Antonio Carrazza (2004, p. 449) define tal competência: “... é a possibilidade de criar, in abstracto, tributos, descrevendo, legislativamente, suas hipóteses de incidência, seus sujeitos ativos, seus sujeitos passivos, suas bases de calculo e suas alíquotas".

Portanto, a competência tributária decorre diretamente da Constituição, ou seja, somente esta poderá definir a quem cabe a criação de um determinado tributo. O exercício da competência tributária tanto pela União quanto os Estados e o Distrito Federal e os Municípios está submetido diretamente às normas constitucionais.

A competência tributaria está definida nos no Capítulo I do Título VI, da Constituição Federal, Do Sistema Tributário Nacional, distribuindo-a de maneira cuidadosa e exaustiva entre as pessoas políticas. 
Conclui-se, pois, que quando uma pessoa política produz norma jurídica tributária que da competência de outra pessoa política, esta norma é inconstitucional, pois desrespeito o disposto na Constituição Federal.

O ilustre professor supra-citado afirma caracterizar-se a competência tributária pela: privatividade, indelegabilidade, incaducabilidade, inalterabilidade, irrenunciabilidade e facultatividade do exercício.

Para o estudo em questão, apenas analisa-se a característica da privatividade.

\subsection{Privatividade da competência tributária}

Roque Antônio Carrazza (2004, p. 464-465) leciona: "No Direito brasileiro, a União, os Estados, os Municípios e o Distrito Federal, no tocante à instituição de tributos, gozam de privatividade, ou se preferirmos, de exclusividade. A bem dizer, todos eles tem faixas tributárias privativas".

Admitir que as pessoas políticas têm privatividade na instituição de tributos significa dizer que em nenhuma hipótese sua competência pode ser exercida por outra pessoa política, não pode nem mesmo haver delegabilidade da competência tributária.

A pessoa política que não possui competência para a criação de um determinado produto não pode usurpar-se na competência de outro, pois caracterizaria invasão de competência, o que é flagrantemente inconstitucional.

Paulo de Barros Carvalho (2002, p. 213), em magistral obra segue o seguinte raciocínio: "Hoje, em obsequio ao rigor das construções dogmáticas, acrescentamos estoutra proposição afirmativa: impostos privativos existem somente os da União".

Para o iminente jurista, a própria Constituição Federal, ao dispor em seu Art 154, II, que a União poderá instituir na iminência ou caso de guerra externa, impostos extraordinários compreendidos ou não em sua competência tributária, os quais serão suprimidos gradativamente, cessadas as causas de sua criação, abre brecha para que o legislador federal venha a exercitar, neste caso, sua competência em tributos de competência das demais pessoas políticas.

Entretanto, mesmo com todos os créditos conferidos a tese do ilustríssimo doutrinador, adotando-se a posição de Roque Antônio Carrazza, mesmo com a exceção disposta no Art 154, II, da CF, goza de privatividade a competência tributaria dos das demais 
A invasão da União na competência dos Estados e do Distrito Federal na contribuição de intervenção do domínio econômico incidente sobre a importação e a comercialização de petróleo e seus derivados, gás natural e seus derivados, e álcool combustível

pessoas políticas. Aqui, apenas se caracteriza uma exceção à regra geral. Toma-se esta posição, pois, não haveria privatividade apenas se a Constituição admitisse a bi-tributação, ou seja, duas pessoas políticas distintas tributarem o mesmo fato imponível, e não em uma hipótese excepcional, como a do artigo em questão.

\section{Da contribuição de intervenção no domínio econômico incidente sobre a} importação e a comercialização de petróleo e seus derivados, gás natural e seus derivados e álcool combustível

Antes de tratar da CIDE dos combustíveis, imprescindível tecer algumas considerações a respeito das Contribuições Especiais em geral, tratadas no Art 149 da Constituição Federal (adotar-se-á aqui a denominação Contribuição Especial de Geraldo Ataliba).

As Contribuições Especiais podem ser de três espécies: as sociais, as corporativas e as interventivas.

Figura jurídica introduzida pela Constituição de 1.988, em seu Art 149, confere à União competência exclusiva para instituir as espécies citadas de contribuição, observando os dispostos nos Arts. 146, III e 150, I e III.

No que concerne às Contribuições de Intervenção no Domínio Econômico, existem diversos problemas e controvérsias, não chegando a doutrina a um senso comum.

Dentre eles, de relevância para o presente estudo, quanto a natureza jurídica deste tributo e o regime jurídico aplicável.

Nos tópicos seguintes apenas será tratado das questões relativas à CIDE dos combustíveis, quanto a sua natureza jurídica, o regime aplicável e seu critério material, conforme a teoria da Regra-Matriz de Incidência Tributária.

\subsection{Natureza jurídica}

Tanto a doutrina quanto a jurisprudência, quase que em sua totalidade estão pacificadas no sentido de afirmar que a natureza jurídica das Contribuições Especiais é de um tributo. 
Esta conclusão decorre da analise do Art 149, Caput, da CF, onde prescreve que estas Contribuições se submetem ao disposto nos Art. 146, III e 150, I e III, do mesmo diploma.

Como afirma Hugo de Brito Machado (2004, p. 389): “É induvidosa, hoje, a natureza tributária destas contribuições. Aliás, a identificação da natureza jurídica de qualquer imposição do Direito só tem sentido pratico porque define seu regime jurídico, vale dizer, define quais são as normas jurídicas aplicáveis".

Pode-se extrair desta afirmação que a natureza jurídica do instituto é que vai definir quais serão as normas aplicáveis a esta Contribuição Especial.

Visto que sua natureza jurídica é de um tributo, surge a questão: seria a CIDE dos combustíveis um tributo com características próprias ou um tributo com características de imposto ou taxa?

Roque Carrazza (2004, p. 533), afirma categoricamente: "Estamos, portanto, que estas contribuições são verdadeiros tributos (embora qualificados pela finalidade que devem alcançar). Podem, pois, revestir a natureza jurídica de imposto ou taxa, conforme a hipótese de incidência e a base de calculo que tiverem".

Tem fundamento a explicação do renomado jurista, assim como leciona Geraldo Ataliba (2004, p. 197), no Brasil, ainda não houve uma Contribuição Especial com características puramente de contribuição, o que há são verdadeiros impostos ou taxa disfarçados pelo nome de contribuição.

Para se definir se a CIDE dos combustíveis se submeta a natureza de um imposto ou de uma taxa é preciso analisar, através de sua hipótese de incidência se este é um tributo vinculado ou não a uma ação estatal.

Assim leciona Geraldo Ataliba (2004, p. 197): “..o que constitucionalmente é designado por contribuição, no Brasil, pode ter hipótese de incidência de verdadeira contribuição ou de imposto".

Se a sua cobrança não estiver vinculada a uma ação estatal será um imposto. Já se se tratar de um tributo devido relativo a uma prestação, por parte da Administração Pública, de serviço publico especifico e divisível ou pelo exercício do poder de polícia será uma taxa. 
A invasão da União na competência dos Estados e do Distrito Federal na contribuição de intervenção do domínio econômico incidente sobre a importação e a comercialização de petróleo e seus derivados, gás natural e seus derivados, e álcool combustível

\subsection{Regime jurídico aplicável}

Quanto ao regime jurídico aplicável a CIDE dos combustíveis, decorrente de sua natureza jurídica, inegavelmente é o regime jurídico tributário.

No entanto, discute-se se é aplicável o Regime de Direito Tributário Puro ou um Regime de Direito Misto, mesclando algumas normas de Direito Tributário e outras de Direito Financeiro.

Não há razão para se afirmar que é aplicável um regime misto. Os doutrinadores que advogam esta tese levam e consideração a destinação da receita do tributo como parte integrante da hipótese de incidência das Contribuições Especiais. Entretanto, esta matéria é de Direito Financeiro, não se confundindo com o Direito Tributário.

Acolher essa tese traria problemas atinentes ao Direito Financeiro para o campo do Direito Tributário, deixando este de cumprir seu papel, ou seja, cuidar apenas da parte da arrecadação das receitas referentes ao Direito Financeiro, passando a tratar da destinação destas receitas.

Portanto, o regime aplicável as Contribuições Especiais é o de Direito Tributário Puro, estando submetidas a todas as regras que se submetem os demais tributos. Especialmente no caso da CIDE dos combustíveis, estaria submetida ao regime próprio dos impostos.

Neste sentido Geraldo Ataliba (2004, p. 192): “Nesse plano, não se pode desconhecer que toda exigência coativa de cunho patrimonial que o estado faça aos sujeitos à sua ordem jurídica se submete à disciplina constitucional. Se tal exigência traduzir-se em dinheiro, então o regime que se lhe aplica é o tributário".

\subsection{Critério material da hipótese de incidência}

Aplicando a Regra-matriz de incidência tributária à CIDE dos combustíveis, é possível extrair seu critério material, de forma a analisar se o tributo em questão tem hipótese de incidência de uma verdadeira Contribuição ou se sua hipótese é de um imposto ou de uma taxa.

Disposto pelo Art 177, § 4ㅇ da Constituição Federal e reafirmado pelo Art 1ํ, Caput, da Lei no 10.336/01 (Lei que criou a CIDE dos Combustíveis), o critério material da exação em 
questão é bivalente, ou seja, dois são os fatos sobre os quais incide a hipótese tributaria: importar e comercializar petróleo e seus derivados, gás natural e seus derivados e álcool combustível.

Para o presente trabalho, apenas será objeto de estudo o critério matéria da hipótese comercializar, pois é nele em que reside o problema da invasão de competência por parte da União.

Antes de tratamos especificamente desse critério material, é necessário remeter a linha de raciocínio aos dois itens anteriores.

Com já verificado, Geraldo Ataliba (2004, p. 193) ensina que uma contribuição pode se revestir de natureza jurídica de um imposto, de uma taxa ou de uma verdadeira contribuição.

O que definira de qual natureza ela se reveste é sua hipótese de incidência. A CIDE dos combustíveis tem por hipótese de incidência fatos jurídicos que a constituição já reservou a impostos, importar, de competência da União (Art 153, I, CF), e comercializar, de competência dos Estados e do Distrito Federal (Art 155, II, CF).

Conclui-se, pois, que a CIDE dos combustíveis reveste-se de natureza jurídica de imposto, sendo aplicável a ela todas as normas constitucionais aplicáveis aos impostos.

\section{Da invasão da União na competência dos Estados e do Distrito Federal frente ao critério material da hipótese de incidência tributária comercializar}

A Emenda Constitucional 33 de 11 de Dezembro de 2001, ao acrescentar o §4으 ao Art. 177 da CF, dispondo que um dos critérios materiais da CIDE dos combustíveis ocorreria quando da comercialização de petróleo e seus derivados, gás natural e seus derivados e álcool combustível, acabou por usar hipótese de incidência própria do ICMS, previsto no Art 155, II, CF.

Ocorre que, o Art. 149, Caput, CF, prescreve que: "Compete exclusivamente à União instituir contribuições sociais, de intervenção no domínio econômico e de interesse das categorias profissionais ou econômicas...".

Já o Art. 155 da CF trata dos impostos de competência dos Estados e do Distrito Federal. Ressalte-se: a competência tributária é privativa, não podendo em hipótese alguma, 
A invasão da União na competência dos Estados e do Distrito Federal na contribuição de intervenção do domínio econômico incidente sobre a importação e a comercialização de petróleo e seus derivados, gás natural e seus derivados, e álcool combustível

exceto a prevista pelo Art 154, II da CF, outra pessoa política usurpar a competência tributária da pessoa política a qual pertence.

Roque Carrazza (2004, p. 541) advoga nesse sentido: "As contribuições interventivas não poderão ter materialidade de tributos de competência tributária dos Estados, dos Municípios ou do Distrito Federal".

Continua: “... não lhe será permitido instituir uma contribuição de intervenção no domínio econômico, sobre venda de mercadorias, justamente porque a tributação das operações mercantis foi reservada, pela Lei Maior, à tributação dos Estados lo que eles fazem, por meio do ICMS)" (CARRAZZA, 2004, p.542).

No mesmo sentido Geraldo Ataliba (2004, p. 201): “...a invocação da designação contribuição não pode servir de escusa para a União desrespeitar os campos de competência tributária privativa dos Estados e dos Municípios." Para Paulo Roberto Lyrio Pimenta (2002, p. 60): "A União não pode invadir a competência dos demais entes tributantes, escolhendo qualquer dos pressupostos indicados nos arts. 155 e 156 do Texto Magno".

Atente-se ainda para o fato de a CIDE dos combustíveis ser uma Contribuição revestida de natureza jurídica de Imposto, sendo aplicáveis a ela o regime jurídico desta espécie de tributo, o que reforça ainda mais a tese de que a União não pode tributar está hipótese de incidência, que é de competência dos Estado e do Distrito Federal.

Portanto ao indicar a hipótese de incidência descrita pelo verbo comercializar, o legislador introduziu na Constituição um dispositivo inconstitucional, pois houve invasão por parte da União na competência tributária dos Estados e do Distrito Federal.

Sustenta opinião Geraldo Ataliba (2004, p. 201) no sentido de que ocorrendo invasão de competência, as contribuições serão inconstitucionais: "...as contribuições, no direito positivo brasileiro, poderão ter hipótese de incidência de imposto federal; se configurarem invasão de competência tributária de Estados e Municípios, serão inconstitucionais".

Desta forma, chega-se à conclusão de que a Contribuição de Intervenção no Domínio Econômico sobre a Importação e a Comercialização de Petróleo e seus Derivados, Gás Natural e seus Derivados e Álcool Combustível tem a mesma hipótese de incidência de um tributo de competência tributária Estadual e Distrital, ocorrendo invasão de competência 
por parte da União. Isto caracteriza a inconstitucionalidade relativa ao critério material da hipótese de incidência descrito pelo verbo comercializar.

\section{Conclusão}

A competência tributária descrita na Carta Magna é decorrente do principio federativo e do principio da autonomia patrimonial, sendo que cada pessoa política exerce essa competência de forma privativa, não podendo delegar nem vê-la usurpada por outra pessoa política, sob pena de inconstitucionalidade de tal ato.

A CIDE tem natureza jurídica de um tributo, podendo se revestir da forma de imposto ou taxa ou mesmo de uma contribuição (Geraldo Ataliba), conforme a hipótese de incidência que adotar.

A CIDE está submetida ao regime jurídico tributário puro, sendo assim, a ela se aplicarão todas as disposições referentes aos tributos, em especial, aquele que sua natureza se revestir. Portanto, se tiver natureza de imposto, se submeterá as regras constitucionais referentes a esse tributo, se tiver natureza de taxa, adotara as regras referentes a essa espécie.

O Critério Material da hipótese de incidência da CIDE dos combustíveis é o mesmo dos impostos previstos pelos Arts., 153, I e 155, II, ambos da CRFB. Portanto, esta Contribuição se reveste da natureza jurídica de imposto, sendo submetida ao mesmo regime tributário dessa espécie, ou seja, ao regime tributário puro, em particular aplicado aos impostos.

Ao instituir hipótese de incidência sobre a comercialização de petróleo e seus derivados, gás natural e seus derivados e álcool combustível, houve invasão por parte da União na competência dos Estados e do Distrito Federal, pois o critério material comercializar é o mesmo do ICMS, imposto de competência destes.

Desta forma, considerando que as Emendas Constitucionais são produtos do Poder Constituinte Derivado Reformador, o qual pode ser objeto de controle de constitucionalidade, tem-se que a Emenda n. 33/01 pode ser declarada inconstitucional mediante Ação Declaratória competente, processada e julgada perante o Supremo Tribunal Federal, eis que eivada de vício material, consubstanciado na invasão da competência dos Estados e do Distrito Federal por parte da União. 
A invasão da União na competência dos Estados e do Distrito Federal na contribuição de intervenção do domínio econômico incidente sobre a importação e a comercialização de petróleo e seus derivados, gás natural e seus derivados, e álcool combustível

\section{Referências}

ATALIBA, Geraldo. Hipótese de Incidência Tributária. 6. ed. São Paulo: Malheiros Editores, 2004.

CARRAZZA, Roque Antônio. Curso de Direito Constitucional Tributário. 20. ed. São Paulo: Malheiros Editores, 2004.

CARVALHO, Paulo de Barros. Curso de Direito Tributário. 14. ed. São Paulo: Saraiva, 2002.

MACHADO, Hugo de Brito. Curso de Direito Tributário. 24. ed. São Paulo: Malheiros Editores, 2004.

PIMENTA, Paulo Roberto Lyrio. Contribuições de Intervenção no Domínio Econômico. São

Paulo: Dialética, 2002. 
Revista de DiReito Público, LondRINA, V. 2, N. 3, P. 35-46, SET./DEZ. 2007. 